\title{
Dermatitis herpetiformis
}

INSERM

\section{Source}

INSERM. (1999). Orphanet: an online rare disease and orphan drug data base. Dermatitis herpetiformis. ORPHA:1656

Dermatitis herpetiformis (DH) is a chronic autoimmune subepidermal bullous disease characterized by grouped pruritic lesions such as papules, urticarial plaques, erythema, and herpetiform vesiculae, with a predominantly symmetrical distribution on extensor surfaces of the elbows (90\%), knees (30\%), shoulders, buttocks, sacral region, and face of children and adults. Erosions, excoriations and hyperpigmentation usually follow. DH may also appear as a consequence of gluten intolerance. 